\title{
Obituary: Steven Klepper
}

\author{
Uwe Cantner • Elias Dinopoulos • Horst Hanusch • Luigi Orsenigo • \\ Nathalie Lazaric • Kenneth I. Carlaw • Roberto Fontana • Charles McCann • \\ Andreas Pyka
}

Published online: 19 June 2013

(C) Springer-Verlag Berlin Heidelberg 2013

On May 27, 2013, our dear friend, colleague, and former Editor of the Journal of Evolutionary Economics (1996-2004), Steven Klepper, passed away in Pittsburgh at the age of 64, after a long struggle with ill health. He was in the company of his loving family.

Steven Klepper was born in 1949. He began his economics education at Cornell University, awarded a BA in 1970 and MA in 1972, and received his PhD degree there in 1975, under the supervision of Dennis Mueller. He then held academic appointments as Assistant Professor of economics at State University of New York at Buffalo from 1974 to 1980 . While there he got to know Michael Gort, a meeting that turned out to be of pivotal importance for Steve's career. In 1980, he moved to Carnegie Mellon University, first as visiting assistant professor, becoming an associate professor in 1984 and a full professor in 1991. From 2003, he held an endowed chair, the

\footnotetext{
U. Cantner $(\triangle)$

University of Jena, Carl-Zeiss-Strasse 3, 07743 Jena, Germany

e-mail: uwe.cantner@uni-jena.de

E. Dinopoulos

Warrington College of Business, Department of Economics, University of Florida, Gainesville, FL 32611-7140, USA

e-mail: elias.dinopoulos@warrington.ufl.edu

H. Hanusch

University of Augsburg, Universitätsstrasse 16, 86135 Augsburg, Germany

e-mail: horst.hanusch@wiwi.uni-augsburg.de

L. Orsenigo

IUSS (University Institute of Advanced Studies), V. le Lungo Ticino Sforza 56, 27100 Pavia, Italy

L. Orsenigo

KITeS Research Center, Università Bocconi, Via Guglielmo Roentgen, 1, 20136 Milan, Italy

e-mail: luigi.orsenigo@unibocconi.it
} 
Arthur Arton Hammerschlag Professorship, and a joint appointment at the Dietrich College of Humanities and Social Sciences and the Tepper School of Business.

Among the honors Steve received at Carnegie Mellon was the lifetime teaching award in 2001. He was awarded the Schumpeter Prize in 2002 for his paper "The Evolution of the U.S. Automobile Industry and Detroit as its Capital". In 2011, he received the Global Award for Entrepreneurship Research. Other awards include his membership in the Phi-Kappa-Phi Society, the oldest, largest and most selective all-discipline honor society in the US, and an honorary doctoral degree from the Department of Economics and Business Administration of the Friedrich Schiller University Jena, which was awarded in 2008.

Steve's research ranged from econometric models, law and economics, and the economics of tax evasion, to industrial organization and innovation. In each of these areas, he published widely in first-rate academic journals. However, we would like to concentrate on Steve's work in industrial and innovation economics. By this we do not wish to deny his high achievements in other fields, but rather to note that his work on industrial organization and innovation should be evaluated even higher, as it stands out for its originality and impressive impact on the profession.

Indeed, Steve created his own brand of research in industrial organization and innovation. Over the last nearly 30 years, Steve developed a branch of research that one can summarize as the search for regularities in the evolution of prominent oligopoly markets. He developed a theory of the industry life cycle and, above all, he set a standard for rigorous research in this field, integrating historical, statistical and theoretical analysis. He used case studies to explore the stylized facts of the evolution of oligopolies and then applied these stylized facts to formulate and to estimate a general model of the evolution of markets, known as the Klepper model. In his

\author{
N. Lazaric \\ University of Nice Sophia Antipolis, Valbonne, France \\ e-mail: nathalie.lazaric@gredeg.cnrs.fr

\section{K. I. Carlaw} \\ University of British Columbia, Kelowna, BC, Canada \\ e-mail: Kenneth.Carlaw@ubc.ca \\ R. Fontana \\ University of Pavia, Pavia, Italy \\ R. Fontana \\ Bocconi University, Milan, Italy \\ e-mail: roberto.fontana@unibocconi.it \\ C. McCann \\ University of Pittsburgh, Pittsburgh, PA, USA \\ e-mail: crmccann@aol.com \\ A. Pyka \\ University of Hohenheim, Stuttgart, Germany \\ e-mail: a.pyka@uni-hohenheim.de
}


work, empirical analysis was used to explore stylized facts, with the theory guided and inspired by these facts.

As one of the main editors of the Journal of Evolutionary Economics from 1996 to 2004, Steve was very much successful in attracting sophisticated articles and pushing the journal forward, increasing its reputation. He followed a special strategy of integrating the work of promising young scholars into the journal by setting up a special topics section.

Those of us who got to know Steve experienced a highly sophisticated and highly renowned professor of economics, a dedicated teacher to all of us, and a warm friend.

Steve Klepper will live on in our memories. We offer our sincere condolences to his family and relatives, especially his wife Florence Rouvier and his daughter, Arielle, and son, Julian.

Jena, Gainesville, Augsburg, Pavia/Milano, Nice, Kelowna, Pittsburgh, Stuttgart, June 2013. 